\title{
The Role of Urinary Cadmium on Liver Function and Erythrocytes Cell Count in Pregnancy
}

\author{
Adjar Wibowo, Firrar Artmi Rahaju, Iskandar, and Eko Suhartono
}

\begin{abstract}
Cadmium (Cd) is a heavy metal, which is used in many industries and was confirmed as an environmental toxin and mainly effects haematological system and liver. Previous studies showed that $\mathrm{Cd}$ induced damage of the liver and influenced erythrocytes. The effect of $\mathrm{Cd}$ in haematological system and liver function especially in pregant women has not been much studied. Thus our study aimed to evaluate the potential effect of cadmium exposure on erythrocytes and liver function in pregnant women by measuring their correlation on the number of erythrocytes and the levels of Aspartate Transaminase (AST) and Alanine Transmainase (ALT). This study was performed between July to December 2013 and targeted 58 pregnant women who were admitted for treatment and termination of pregnancy due to medical or obstetrical indications in Mutiara Bunda Mother and Child Hospital, Martapura, South Kalimantan, Indoneseia. For analyzing of the data, SPSS software version 17 was used and was examined by Pearson correlation test. We found that $\mathrm{Cd}$ has a negative correlation with erythroctes cell count and ALT levels and a positive correlation with AST levels, but the three correlations are not significant on statistical analysis. It can be concluded from our results $\mathrm{Cd}$ caused erythrocytes cells and tissue damage but did not cause liver damage.
\end{abstract}

Index Terms-Alanine transaminase, aspartate transmainase, cadmium, erythrocytes, pregnant women.

\section{INTRODUCTION}

Industrial development has brought man into contact with several persistent chemicals, including heavy metals, such as cadmium (Cd) [1]. $\mathrm{Cd}$ is a heavy metal with great environmental health effects and all $\mathrm{Cd}$ compounds have been classified as human carcinogens. $\mathrm{Cd}$ is used industrially to manufacture electro-plates, batteries, alloys and fuels [2].

$\mathrm{Cd}$ contamination of environment is a subject of serious international concerns since the metal is known to enter the food chain and can undergo bioaccumulation, endanger human health [3]. Cd is hazardous both by inhalation and ingestion and can cause acute and chronic intoxications [4]. It

Manuscript received February 6, 2014; revised April 21, 2014

Adjar Wibowo is with the Obstetry and Gynecology Department Ulin General Hospital/Faculty of Medicine Lambung Mangkurat University, Indonesia (e-mail: Adjarwibowo@yahoo.com).

Firrar Artmi Rahaju is with the Mutiara Bunda Mother and Child Hospital, Martapura, South Kalimantan, Indonesia (e-mail: fir_art@yahoo.com).

Iskandar is with Research Unit Mutiara Bunda Mother and Child Hospital, Martapura of South Kalimantan, Indonesian (e-mail: Iskandarthalib@gmail.com).

Eko Suhartono is with Environmental Science and Technology Graduate Program, University of Brawijaya, Malang, Indonesia and Medical Chemistry/Biochemistry Department Faculty of Medicine University of Lambung Mangkurat, Banjarmasin, Indonesia (e-mail: ekoantioxidant@gmail.com). is absorbed from gastrointestinal tract to blood, and $\mathrm{Cd}$ is taken up from the blood into the tissues. The $\mathrm{Cd}$ accumulates in human and animals tissues, especially the liver and kidney, causing their damage. Then $\mathrm{Cd}$ cause reduced feed intake and weight loss, decreased red blood cell (RBC) and blood haemoglobin $(\mathrm{Hb})$ values and anaemia [5].

Cadmium exerts its toxic effects via oxidative damage to cellular organelles by inducing the generation of reactive oxygen species (ROS) which consist mainly of $\bullet \mathrm{O}_{2}, \mathrm{H}_{2} \mathrm{O}_{2}$ and -OH. The molecular mechanism by which the generation of free radicals are far from being understood but reports have indicated that $\mathrm{Cd}$ does this via direct phenomenon. Reactions of these ROS with cellular biomolecules have been shown to lead to lipid peroxidation, membrane protein damage, altered anti oxidant system, DNA damage, altered gene expression and apoptosis [3].

We have seen that cadmium induced lipid peroxidation disturbs membrane integrity as well as cell functions. Membrane integrity is very important for the function of all cells in the body, but it must have a vital importance for red blood cells which carry 200 or 300 million molecules of hemoglobin in each one. For normal tissue oxygenation, iron atoms in hemoglobin molecules must be protected from oxidative stress and this protection requires a normal red blood cell membrane, a leakage of hemoglobin into plasma, a tendency of intravascular hemolysis and a deficiency in tissue oxygenation would occur [6].

Besides the above mentioned, acute exposure to $\mathrm{Cd}$ in vivo causes dysuria, polyuria, chest pain, fatigue, headache, and hepatooxidative [7]. Chronic intake of $\mathrm{Cd}$ in contaminated food or air produces organ dysfunction as a result of cell death, resulting in pulmonary, hepatic and renal tubular diseases [8]. The liver is the most important target organ when considering $\mathrm{Cd}$-induced toxicity because $\mathrm{Cd}$ primarily accumulates in the liver [7].

The liver is one of the most susceptible organs after acute or chronic exposure to $\mathrm{Cd}$ [9]. Upon acute exposure to cadmium, hepatotoxicity is indicated by changes such as swelling of hepatocytes, fatty changes, focal necrosis, hepatocytes degeneration and impaired functions of biomarkers of liver function such as aspartate aminotransferase (AST) and alanine aminotransferase (ALT). On electron microscopy, changes such as dilatation of ribosomes, damage of membrane-bounded lysosomes, nuclear pyknosis, were reported [9], [10].

The previous study showed Cd induced damage of the liver is manifested by an increase in AST and ALT in the blood [9]. The study showed that $\mathrm{Cd}$ induced oxidative damage in liver by increasing MDA and peroxide level [7].

To our knowledge, data on correlation of heavy metals with haematological system especially erythrocytes and liver 
function during pregnancy have been missing in the scientific literature. Therefore, this work focuses on correlation between Cd levels with erythrocytes cell count, ALT and AST levels during pregnancy. Heavy metals were monitored during the pregnancy period, when they were transported from the maternal organism through the placenta to foetuses [11]. Thus our study aimed to evaluate the potential effect of cadmium exposure on erythrocytes and liver function in pregnant women by measuring their correlation on the number of erythrocytes and the levels of AST and ALT.

\section{MATERIAL AND METHODS}

This analytic descriptive study was carried out in mother treatment ward of Mutiara Bunda Mother and Child Hospital in Martapura. This study was performed between July to December 2013 and targeted 58 pregnant women who were admitted for treatment or termination of pregnancy due to medical or obstetrical indications. The gestational age of all pregnant women is between 37-42 weeks. The subjects were all Indonesian living in the areas close to the hospital. No significant different characteristics of socioeconomic status, nutrition, and health management, were found among them. Informed consent for this study was obtained from the subjects in the appropriate manner. For each participant, $3 \mathrm{ml}$ venous blood were withdrawn from anticubital vein under complete aseptic condition, added to EDTA. Maternal urine samples were collected into tubes. All blood and urine sample were taken before child birth process. All sample were examined in Mutiara Bunda Mother and Child Hospital Laboratory.

\section{A. Urinary Cadmium Analysis}

Urinary cadmium levels were analyzed by approach to adjust urinary specific gravity based on Vij and Howell formula [12].

\section{B. Alanine Transaminase (ALT) Assay}

The alanine transaminase (ALT) in the plasma and tissue homogenate was estimated by the method of Reitman and Frankel [13].

The assay is based on the following reaction of the enzyme:

$$
\text { Glutamate }+ \text { pyruvate } \rightleftharpoons \alpha \text {-ketoglutarate }+ \text { alanine }
$$

By reaction with 2, 4, dinitrophenylhydrazine, the keto acid produced (in the equation above) will then form the corresponding colored hydrazone.

The assay forthe enzyme was carried out by adding $0.2 \mathrm{ml}$ of serum sample to $1 \mathrm{ml}$ of ALT buffered substrate. The mixture was incubated at $37^{\circ} \mathrm{C}$ for 30 mins. After incubation, $1 \mathrm{ml}$ of color reagent $(2,4$, dinitrophenylhydrazine) was added to the mixture. The solution was allowed to stand at room temperature for $20 \mathrm{mins}$. Sodium hydroxide $(10 \mathrm{ml}$ of $0.4 \mathrm{M}$ $\mathrm{NaOH}$ ) was then added, mixed and allowed to stand for at least five minutes. A blank containing $0.2 \mathrm{ml}$ of distilled water was similarly treated. Absorbance of the sample was read against the blank at $505 \mathrm{~nm}$.

\section{Aspartate Transaminase (AST) Assay}

The Aspartate transaminase in the plasma and tissue homogenate was estimated by the method of Reitman and Frankel [13].

The assay is based on the following reaction:

Aspartate (Asp) $+\alpha$-ketoglutarate $\leftrightarrow$ oxaloacetate+ glutamate Procedure for the assay of AST was carried out by adding $0.2 \mathrm{ml}$ of serum sample to $1 \mathrm{ml}$ of AST buffered substrate. The mixture was incubated at $37^{\circ} \mathrm{C}$ for $60 \mathrm{mins}$. After incubation, $1 \mathrm{ml}$ of color reagent (2, 4,dinitrophenylhydrazine) was added to the mixture. The solution was allowed to stand at room temperature for 20 mins. Sodium hydroxide $(10 \mathrm{ml}$ of $0.4 \mathrm{M} \mathrm{NaOH})$ was then added, mixed and allowed to stand for at least five minutes. A blank containing $0.2 \mathrm{ml}$ of distilled water was similarly treated. Absorbance of the sample was read against the blank at $505 \mathrm{~nm}$.

\section{Erythrocytes Cell Count}

Erythrocytes cell count were measured by using a fully automatic blood cell counter, Mindray-2800.

\section{E. Statistical Analysis}

For analyzing of the data, SPSS software version 17 was used and was examined by Pearson correlation test. For all outcomes, a nominal $p$-value of $p<0,05$ was considered significant.

\section{RESUlTS}

Based on the result of this study we found data from 58 samples. The characteristic data for those samples shown at Table I.

TABLE I: MATERNAL DEMOGRAPHIC AND CLINICAL CHARACTERISTIC $(\mathrm{MEAN} \pm \mathrm{SD})$ IN PREGNANT WOMEN

\begin{tabular}{lc}
\hline \hline Parameters & Value \\
\hline Age (years) & $28,66 \pm 5,42$ \\
Systolic Blood Pressure $(\mathrm{mmHg})$ & $120,34 \pm 16,22$ \\
Diastolic Blood Pressure $(\mathrm{mmHg})$ & $79,83 \pm 2,15$ \\
Number of Preganacy (times) & $1,98 \pm 1,10$ \\
Gestational Age (weeks) & $39,28 \pm 2,15$ \\
Urinary Cd Level $(\mu \mathrm{g} / \mathrm{L})$ & $0,4007 \pm 0,33$ \\
\hline \hline
\end{tabular}

Table I showed that the age, number of pregnancy, gestational age, urinary $\mathrm{Cd}$ level, systolic and diastolic blood pressure.

Liver function test that we used were Alanine Transaminase (ALT) and Aspartate Transaminase (AST). Haemotological test that we used were erythrocytes cell count. Those results are presented in Table II.

TABLE II: LIVER FunCTION TEST AND ERYTHROCYTES CELL COUNT (MEAN \pm SD) IN PREGNANT WOMEN

\begin{tabular}{lc}
\hline \hline Parameters & Value \\
\hline Alanine Transaminase (ALT) (U/I) & $26,91 \pm 8,85$ \\
Aspartate Transaminase (AST) (U/I) & $33,74 \pm 12,49$ \\
Erythrocytes cell count (Million/mm $\mathrm{mm}^{3}$ ) & $4,23 \pm 0,43$ \\
\hline \hline
\end{tabular}

Pearson correlation between $\mathrm{Cd}$ exposure on liver function and erythrocyte cell count of pregnant women that there are not significant correlation between Cd and ALT, AST and Erythrocytes cell count (Table III). But from the correlation it seems Cd induced the increasing of AST and the decreasing 
of ALT and erythrocytes cell count.

TABLE III: CORRELATION BETWEEN URINARY CADMIUM WITH ALT, AST AND ERYTHROCYTES CELL COUNT

\begin{tabular}{lrc}
\hline \hline \multirow{2}{*}{ Correlation } & \multicolumn{2}{c}{$\mathrm{Cd}$} \\
\cline { 2 - 3 } & $\mathrm{r}$ & $\mathrm{P}$ \\
\hline Alanine Transaminase (ALT) & $-0,41$ & 0,760 \\
Aspartate Transaminase (AST) & 0,81 & 0,544 \\
Erythrocytes cell count & $-0,73$ & 0,588 \\
\hline \hline
\end{tabular}

\section{DISCUSSION}

It is well known that chronic Cd intoxication can induce anemia. The mechanism by which cadmium results in anaemia is still under investigation. However, some of the proposed mechanisms include decreased iron absorption, distortion of erythropoiesis and haemolysis of red blood cells [9], [14].

The present study showed that $\mathrm{Cd}$ negatively correlated with eryhrocytes but not significant. It means greater levels of $\mathrm{Cd}$ in the body of the cell will be reduced by erythrocyte cell count. Our result suggest that $\mathrm{Cd}$ is already affecting erythrocytes. Available reports indicate that cadmium-induced toxicity results from the generation of free radicals, which leads to lipid peroxidation, causing damage to many systems and organs and a change in their functions and structure [9]. The integrity and function might be disturbed because of the peroxidation of lipid. Membrane integrity is very important for the function of all cells in the body, but it must have a vital importance for red blood cells which carry 200 or 300 million molecules of hemoglobin in each one [6].

These results have been shown by other authors. It is likely that the high dose of mercury and the combination of high doses of cadmium and mercury do reduce the number of red blood cells causing anemia in Wistar rats intoxicated. Mercury and the combination of high concentrations of cadmium and mercury could inhibit heme synthesis of red blood cells and cause anemia signs described by Bottomley and Muller-Eberhard [14].

The liver is a vital organ presented in vertebrates and some other animals; it lies below the diaphragm in the abdominal-pelvic region of the abdomen, where it performs a wide range of necessary metabolic activities for homeostasis, nutrition and immune defence [15]. The liver's high specialized tissues regulate a wide variety of high-volume biochemical reactions, including the synthesis and breakdown of small and complex molecules, many of which are necessary for normal vital functions [16]. Most of the toxic compounds in the body are metabolized in liver. The entry of these toxicants into the body is principally via the gastrointestinal tract, and after absorption, they are transported through the hepatic vein to the liver [16].

Cadmium (Cd) is a heavy metal that primarily was accumulated in the liver, which becomes a more important target organ for damage. Several mechanisms have been suggested for the induction of cadmium-associated hepatotoxicity. One of the reported mechanisms of cadmium induced liver toxicity is mediated by the upregulation of reactive oxygen species (ROS) (hydroxyl groups, superoxides and hydrogen peroxides) which cause oxidative damage to lipid contents of membrane. Over-production of ROS normally induces oxidative stress unless it was scavenged with endogenous antioxidants. Thus, overproduction of ROS could be attributed to the depletion of antioxidants or to the direct action of cadmium on peroxidation reaction and iron-mediated peroxidation [10].

Primary injury of cells resulting from binding of cadmium to sulfhydryl groups in mitochondria and secondary injury initiated by the activation of kupffer cells have also been mentioned as possible mechanisms of toxic effect of cadmium on the liver. Inactivation of sulthydryl groups causes oxidative stress, mitochondrial permeability transition and mitochondrial dysfunction [17]. It is also suggested that kupffer cells release proinflammatory cytokines and chemokines which stimulate the migration and accumulation of neutrophils and monocytes in the liver. Dudley also suggested that hepatocytes injury may be caused by ischemia due to sinusoidal endothelial cell dysfunction. Cadmium has been found to accumulate in endothelial cells leading to necrosis and denudation of hepatic sinusoids. The hepatotoxicity of cadmium has also been attributed to the formation of toxic metabolites when it is activated by hepatic cytochrome P-450 to a highly active metabolite $\mathrm{N}$-acelyl-P-benzooquinone imine. Furthermore, interference with essential metals could be one of the mechanisms employed by cadmium mediated toxicological effects [10].

Cadmium may interact with elements like zinc, iron, magnesium, manganese, calcium and selenium and cause their secondary deficit thereby disrupting metabolism, resulting in the final morphological and functional changes in many organs. Cadmium has been reported to be involved in the disruption of signaling and biomembranes. This could occur through interaction with cellular components even without entering the cell, by interaction with receptors on their surface [10].

Hepatocellular injury or hepatotoxicity can be attained by quantifying the enzymes ALT and AST. Changes in the levels of these enzymes reveal the variations in the cell membrane functions including the alteration in the permeability which leads to cell damage [18]. Among these two enzymes, measurement of ALT is considered as a good marker to indicate the liver damage particularly in animal species [18].

Positive correlation between Cd levels and AST means the greater levels of Cd will increase the levels of AST. Ast is found in many body tissues including the heart, muscle, kidney, brain and lung. It is also present in the liver [19]. When body tissue or an organ such as heart or liver is damaged, additional AST is released into the bloodstream. The amount of AST in the blood is directly related to the extent of the tissue damage [20].

Otherwise the negative correlation between $\mathrm{Cd}$ levels and ALT means the greater levels of Cd will decrease the level of ALT. It is different with some previous studies. Increased activities of serum AST and serum ALT have been found, and this is in accordance with the results of Nomiyama (1980) and Weigel et al. (1984) who studied the effects of $7.15 \mathrm{ppm}$ dietary cadmium in male Wister rats for 40 and 60 days and found that the activities of serum AST and ALT were increased indicating disturbed hepatic functions. On the same side, Jihan et al. (2009) concluded that selenium and zinc 
protect the liver against oxidative stress induced by $\mathrm{Cd}$ [1].

The negative correlation might be due to $\mathrm{Cd}$ levels being not enough to cause toxicity to the liver. We suggest the cadmium concentration on research results just led to some tissue damages. It can be seen that there is a positive correlation between the levels of AST with Cd levels and negative correlation with ALT levels.

Furthermore, the negative correlation between $\mathrm{Cd}$ levels and ALT migh be due to defense system in human body. The human body has several mechanisms to reduce oxidative stress, such as produced antioxidants, which are either naturally produced inside the body, or externally supplied through foods and/or supplements [20].

Antioxidant enzymes which are inside the body are capable of stabilizing, or deactivating free radicals before they attack cellular components. They act by reducing the energy of the free radicals or by giving up some of their electrons for their use, thereby causing them to become stable. In addition, they may also interrupt with the oxidizing chain reaction to minimize the damage caused by free radicals. For the past decade, countless studies have been devoted to the beneficial effects of antioxidant enzymes [21].

Antioxidants are chemical compounds which contain monohydroxy / polyhydroxy phenol; they just work to slow down the lipid peroxidation. These compounds have low activation energy to donate hydrogen atom therefore, they cannot initiate the second free radicals. The free radical electrons are stable and thus, slow down the oxidation. Cells contain many antioxidant systems to prevent injury. Prevention of excessive free radical and repair of cellular damage is essential for cell's life [21].

Antioxidants may be enzymatic or non-enzymatic. A enzymatic system directly or indirectly contributes to defense against free radical. Catalase (CAT), Superoxide dismutase (SOD), glutathione peroxidase (GPx), glutathione reductase, an thioredoxin exhibit biological value. SOD is a metallo protein that catalyses the dismutation of superoxide radicals. CAT is a heme protein which catalyses the reduction of $\mathrm{H}_{2} \mathrm{O}_{2}$ to water and oxygen and thus protects the cell from oxidative damage by $\mathrm{H}_{2} \mathrm{O}_{2}$ and $\bullet \mathrm{OH}$. GPx is a seleno enzyme, which plays a major role in the reduction of $\mathrm{H}_{2} \mathrm{O}_{2}$ and hydroperoxide to non-toxic products [21], [22].

The non-enzymatic antioxidants are actually the scavengers of free radical. These involving glutathone, vitamin $\mathrm{E}$ and $\mathrm{C}$ (inhibits oxidation of membrane lipid), uric acid are the scavengers of peroxynitrite in plasma, albumin, bilirubin, N-Acetylcysteine (NAC), melatonin which directly reacts with free radical form disulfides [21].

Reports have shown that antioxidants like vitamin $\mathrm{C}$ and Vitamin $\mathrm{E}$ have shown protection against cadmium induced toxicity in different animal models. Supplementation of these natural antioxidants reduced ROS levels, lipid peroxidation, haematological values and enzymatic and non-enzymatic components of antioxidant defence system [21].

\section{CONCLUSION}

We found that $\mathrm{Cd}$ has a negative correlation with erythroctes cell count and ALT levels and positive correlation with AST levels, but the three correlation are not significant on statistical analysis. It means $\mathrm{Cd}$ affected erythroctes cells and cause tissue damage but does not caused liver damage.

\section{REFERENCES}

[1] E. Ashraf, M. S. Salem, A. E. Amany, A. R. Zeinab, and M. K. Asmaa "Protective effect of zinc against cadmium toxicity on pregnant rats and their fetuses at morphological, physiological and molecular level," Afr. J. Biotechnol., vol. 12, no. 16, pp. 2110-2119, April 2013.

[2] K. Hamden, S. Carreau, F. A. Mark, H. Masmoudi, and A. Feki, "Positive effects of Green Tea on hepatic dysfunction, lipid peroxidation and antioxidant defence depletion induced by cadmium,' Biol Res., vol. 41, pp. 331-339, 2008.

[3] J. Renugadevi and S. M. Prabu, "Cadmium-induced hepatotoxicity in rats and the protective effect of naringenin," Exp Toxicol Pathol., pp. 1-11, 2009.

[4] E. S. Triawanti, A. S. Leksono, and M. S. Djati, "The role of cadmium in protein glycation by glucose: Formation of methylglyoxal and hydrogen peroxide in vitro," JOMB, vol. 3, no. 1, pp. 59-62, 2014.

[5] K. H. A. Abdo and H. Abdulla, "Effect of cadmium in drinking water on growth, some haematological and biochemical of chicken," Euro. J. Exp. Bio., vol. 3, no. 5, pp. 287-291, 2013.

[6] S. Demir and G. Oner, "The effect of cadmium on the fragility of red blood cell," J. Islm. Acad. Sci, vol. 8, no. 2, pp. 73-78, 1995.

[7] E. S. Triawanti, A. Yunanto, and R. T. F. Iskandar, "Chronic Cadmium hepatooxidative in rats: Treatment with Haruan fish (Channa striata) extract," APCBEE Procedia, vol. 5, pp. 441-445, 2013.

[8] W. Adjar, F. A. Rahaju, R. T. Firdaus, and S. Eko, "The role of urinanry cadmium and lead level on pregnant women renal function," $J O M B$, vol. 3, no. 1, pp. 55-58, March 2014.

[9] S. O. Asagba and G. E. Eriyamremu, "Oral cadmium exposure alters haematological and liver function parameters of rats fed a Nigerian-like diet," J. Nut. Env. Med., vol. 16, no. 3-4, pp. 267-274, September, December 2007.

[10] E. Adikwu, O. Deo, and O.-B. Geoffrey, "Hepatotoxicity of cadmium and roles of mitigating agents," Br. J. Pharmacol. Toxicol., vol. 4, no. 6, pp. 222-231, 2013.

[11] L. Krejcirova, I. Lauschova, and P. Cizek, "Distribution of heavy metals in the liver of foetuses and female mice after oral administration during preganacy - a histochemical study," Acta. Vet. Brno., vol. 79, pp. 225-231, 2010.

[12] T. Sorahan, D. Pang, N. Esmen, and S. Sadhra, "Urinary Concentrations of Toxic Substances: An Assessment of Alternative Approaches to Adjusting for Specific Gravity," JOEH, vol 5, pp. 721-723, Nov. 2008.

[13] S. Reitman and S. Frankel, "A colorimetric method for the determination of serum glutamic oxalacetic and glutamic pyruvic transaminases," American Journal of Clinical Pathology, vol. 28, pp. 56-63, 1957.

[14] A. S. Y. Hounkpatin, R. C. Johnson, P. Guedenon, E. Domingo, C. G. Alimba, M. Boko, and P. A. Edorh, "Protective effects of vitamin C on haematological parameters in intoxicated wistar rats with cadmium, mercury and combined cadmium and mercury," Int. Res. J. Biological Sci., vol. 1, no. 8, pp. 76-81, December 2012.

[15] D. N. Ezejindu, K. C. Chinweife, and C. J. Ihentuge, "The effects of moringa extract on liver enzymes of carbon tetrachloride induced hepatotoxicity in adult wister rats," Int J Eng Sci., vol. 2, pp. 54-59, 2013.

[16] T. M. Olatosin, D. S. Akinduko, and C. Z .Uche, "Evaluation of the hepatoprotective efficacy of Moringa olefeira seed oil on $\mathrm{CCL}_{4}$-induced liver damage in wistar albino rats," Int J Eng Sci, vol. 2, pp. 13-18, 2013.

[17] M. Jurczuk, M. M. Brzoska, J. Moniuszko-Jakoniuk, M. Galazyn-Sidorczuk, and E. Kulikowska-Karpinska, "Antioxidant enzymes activity and lipid peroxidation in liver and kidney of rats exposed to cadmium and ethanol," Food Chem. Toxicol., vol. 42, pp. 429-438, 2004.

[18] M. A. Fahim, A. Nemmar, S. Dhanasekaran, S. Singh, M. Shafiullah, J. Yasin, S. Ziai, and M. Y. Hasan, "Acute cadmium exposure causes systemic and thromboembolic events in mice," Physiol. Res., vol. 61, pp. 73-80, 2012.

[19] D. R. Duffour, J. A. Lott, F. S. Nolte, and D. R. Gretch, "Diagnosis and monitoring of hepatic injury II. Recommendations for use laboratory tests in screening, diagnosis, and monitoring," Clin. Chem., vol. 46, pp. 2050-2068, 2000 
[20] L. A. Maharani, Iskandar, and E. Suhartono, "Bioactive compound and antioxidant activity of methanol extract Mauli bananas (Musa $s p$ ) stem," Int J Bios Biochem Bioinform, vol. 4, no. 2, pp. 110-115, 2014.

[21] S. Noori, "An overview of oxidative stress and antioxidant defensive sytem, "Scientific Reports, vol. 1, no. 8, pp. 1-9, 2012.

[22] S. J. S. Flora, M. Mittal, and A. Mehta, "Heavy metal induced oxidative stress and its possible reversal by chelation therapy," Indian J Med Res, vol. 128, pp. 501-523, October 2008.

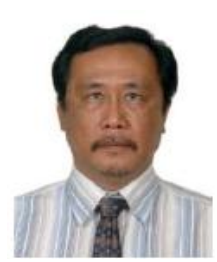

Adjar Wibowo was born in Palembang, Indonesia, in December 1954. He received his obstetric and gynecology specialist medical doctor in 1992 from Sriwijaya University, Palembang, Indonesia and his $\mathrm{Ph} . \mathrm{D}$ in 2005 from Padjajaran University, Bandung, Indonesia. His research is mainly focused on preeclampsia and pregnancy.

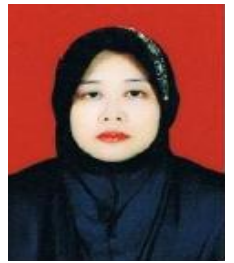

Firrar Artmi Rahaju was born in Yogyakarta, Indonesia, in February 1971. She received her obstetric and gynecology specialist medical doctor in 2005 from Gadjah Mada University, Yogyakarta, Indonesia. She is currently an obstetric and gynecology specialist medical doctor in Mutiara Bunda Mother and Child Hospital, Martapura, Indonesia.

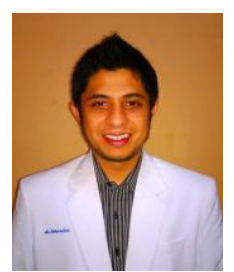

Iskandar was born in Jakarta, Indonesia, in April 1987. He received his medical doctor in 2011 from Lambung Mangkurat University, Banjarbaru, Indonesia. $\mathrm{He}$ is currently a general physician in Mutiara Bunda Mother and Child Hospital, Martapura, Indonesia.

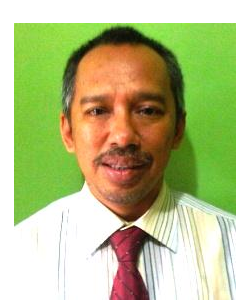

Eko Suhartono was born in Surabaya, Indonesia, in September 1968. He received his Drs. and M.Sc degree in 1991 and 1998 from Gadjah Mada University, Yogyakarta, Indonesia. He currently study environmental science and technology graduate program in Brawijaya University, Malang, Indonesia His research is mainly focused on free radical and natural product antioxidant, ecotoxicology. 